\title{
0 trabalho em plataformas digitais: direitos, COVID-19 e problemas emergentes
}

\author{
Working on digital platforms: rights, COVID-19 and \\ emerging problems
}

\section{Trabajar en plataformas digitales: derechos, COVID-19 y problemas emergentes}

\author{
iD Sidnei Machado \\ Universidade Federal do Paraná, Curitiba, Paraná, Brasil \\ sidneimchd@gmail.com \\ iD Alexandre Pilan Zanoni \\ Universidade Federal do Paraná, Curitiba, Paraná, Brasil \\ alexandrepzanoni@gmail.com
}

\begin{abstract}
Resumo: Apresentamos os resultados de pesquisa sobre o trabalho de entregadores em plataformas digitais. Exploramos metodologias quantitativas e qualitativas de coleta e análise de dados com o objetivo de compreender as construções sobre os direitos e os sentidos de justiça entre os entregadores. No contexto da pandemia da Covid-19, estendemos os objetivos da pesquisa no sentido de captar os seus impactos na remuneração e no tempo de trabalho, bem como compreender o sentido atribuído pelos entregadores da cidade de Curitiba a duas paralisações nacionais que ocorreram no mês de julho de 2020. Apontamos para a formação de solidariedades horizontalizadas e complexas, para a configuração de uma racionalidade profissional e para a necessidade e potencialidade de estudos aprofundados.
\end{abstract}

Palavras-chave: Plataformas digitais. Direitos. Trabalho. Solidariedade. COVID-19. 
Abstract: We present the results of research on digital labor platforms. We explore different techniques and methodologies, quantitative and qualitative, of data collection and analysis in order to understand the constructions of rights and the meanings of justice among delivery workers. In the context of the Covid-19 pandemic, we extended the objectives of the research in order to capture its impacts on remuneration and labor time, as well as to understand the meaning attributed by the delivery workers in the city of Curitiba to two national stoppages that occurred in the month of July 2020. We indicate the formation of horizontal and complex solidarities, the configuration of a professional rationality and the need and potential for in-depth studies.

Keywords: Digital Platforms. Rights. Labour. Solidarity. COVID-19.

Resumen: Presentamos los resultados de una investigación sobre el trabajo de los repartidores en plataformas digitales. Exploramos diferentes técnicas y metodologías, cuantitativas y cualitativas, de recolección y análisis de datos para comprender las construcciones sobre los derechos y los significados de la justicia entre los repartidores. En el contexto de la pandemia COVID-19, ampliamos los objetivos de la investigación con el fin de captar sus impactos en la remuneración y el tiempo de trabajo, así como comprender el significado que atribuyen los repartidores en la ciudad de Curitiba a dos paros nacionales ocurridos en el mes de Julio 2020. Apuntamos a la formación de solidaridades horizontales y complejas, a la configuración de una racionalidad profesional y a la necesidad y potencialidad de estudios en profundidad.

Palabras clave: Plataformas digitales. Derechos. Trabajo. Solidaridad. COVID-19.

Data de submissão: 08/10/2020

Data de aprovação: 19/01/2020 


\section{Introdução}

A difusão de tecnologias da informação e comunicação, como a internet de alta velocidade, e a massificação de dispositivos móveis, como smartphones, possibilitaram o surgimento global de um novo modelo de negócio que desafia as configurações tradicionais do trabalho. São plataformas digitais, com alto poder de processamento e análise de dados, capazes de conectar, a qualquer momento, trabalhadores a consumidores. Esse modelo de negócio adentrou diferentes áreas e setores da economia, dos serviços de acomodação e hotelaria aos serviços de logística e entrega de alimentos.

Neste estudo, precisamente, procuramos compreender as configurações do trabalho nas plataformas digitais de entrega Ifood, UberEats, Rappi e Loggi. Todas elas compartilham a mesma forma de recrutamento e de gerenciamento algorítmico dos entregadores; não estabelecem relações contratuais de natureza empregatícia com base na legislação trabalhista e salientam o caráter meramente tecnológico das suas atividades, cuja única atribuição seria a de mediar a interação entre os prestadores de serviços autônomos e os clientes consumidores. Os entregadores, portanto, atuam por conta própria - informais, autônomos ou pela figura do Microempreendedor Individual (MEI) - sendo remunerados por cada entrega realizada. Assim, por não terem reconhecida a configuração do estatuto de emprego, não estão protegidos por direitos trabalhistas, apesar da presença de um trabalho com longas jornadas, sub-remunerado e de reduzida autonomia.

A primeira questão que a pesquisa procura responder é como os entregadores que trabalham por meio das plataformas digitais entendem a situação em que vivem e se organizam frente às adversidades que enfrentam. Nesta pesquisa, buscamos compreender os problemas enfrentados pelos entregadores e os indícios de solidariedade e resistência frente ao poder das plataformas digitais.

A segunda formulação da presente pesquisa é o trabalho dos entregadores no contexto da pandemia da Covid-19, quando estes 
se tornaram o elo vital na distribuição de alimentos e remédios a milhões de pessoas em situação de isolamento social. Estendemos o alcance desta pesquisa no sentido de compreender os impactos da pandemia na remuneração e no tempo de trabalho desses trabalhadores. Apesar da essencialidade da atividade, a análise de questionários aplicados a entregadores de todo o país, em abril de 2020, evidenciou uma queda expressiva na remuneração, não despercebida pelos próprios entregadores, que em julho organizaram paralisações em todo o país reivindicando um aumento nas "taxas" praticadas pelas plataformas.

A pesquisa analisa, em seguida, a compreensão das pautas e entendimentos dos entregadores da cidade de Curitiba, nas suas particularidades e especificidades locais de prestação de trabalho. Foi utilizada a metodologia de grupo focal, realizado com entregadores e lideranças, para compreender os sentidos atribuídos às temáticas da remuneração e tempo de trabalho e suas opiniões sobre as paralisações nacionais. Como hipótese interpretativa, observamos a formação de consenso em torno da necessidade da construção e da valorização de uma identidade do tipo profissional, bem como de uma "regulamentação mínima" da atividade que abranja todos os entregadores, independentemente da formação de vínculo de emprego com as plataformas. A partir dessa observação de construção da hipótese de pesquisa, apontamos um possível caminho e aprofundamento de pesquisa futura, no sentido de compreender a formação de solidariedades complexas e difusas entre os entregadores.

Reforçamos que os dados apresentados são insuficientes para generalizações de maior escala. Entretanto, a análise desenvolvida foi capaz de colocar em cena problemas emergentes, tanto de pesquisa como reivindicações e desafios enfrentados pelos trabalhadores, expressando, assim, a possibilidade de auxiliar na construção de novas hipóteses e de uma agenda de pesquisa. 


\title{
O modelo de negócio das plataformas digitais
}

\author{
Um panorama do quadro analítico
}

Segundo Degryse (2016), empresas como a Amazon Mechanical Turk, a Uber e a Clickworker expressam o fenômeno da digitalização da economia e emergiram devido ao desenvolvimento recente de três tecnologias: a internet e redes de alta velocidade, a Big Data e o surgimento de novas formas de dispositivos móveis. Degryse (2017) descreve uma "economia das plataformas", cuja principal novidade foi ter trazido à cena a "multidão" como um novo ator, disponível 24 horas por dia, 7 dias por semana, dispersa ao redor do mundo e preparada para trabalhar por uma baixa remuneração. Nesse contexto, além da robotização que impacta o setor industrial, a autora observa que os movimentos sociais e sindicais precisam enfrentar a questão da emergência da multidão e do crowdsourcing - crowd ou multidão em português e sourcing ou fornecimento em português - como fonte de captação e organização do trabalho.

Um retorno das multidões é descrito por Aytes (2013) no contexto das tecnologias da informação. $O$ autor cita a experiência de fracasso da empresa Amazon em criar ferramentas baseadas em inteligência artificial capazes de remover de seu sítio de comércio eletrônico cadastros repetidos de produtos à venda. A empresa então precisou recorrer, por volta do ano de 2007, ao trabalho cognitivo humano e para isso desenvolveu uma das primeiras plataformas digitais de trabalho, a Amazon Mechanical Turk, por meio da qual uma força de trabalho globalmente dispersa é paga por cada um dos cliques que efetua ao completar as tarefas designadas. Essa plataforma atua como fornecedora de mão-de-obra digital para centenas de outras empresas, aplicando o conceito computacional do crowdsourcing, ou seja, o fornecimento de trabalho pela multidão, concebido no paradigma pós-fordista de outsourcing. 
É de se indagar quais os impactos sociais desse novo arranjo do trabalho, ainda mais quando McAfee e Brynjolfsson (2017) sintetizam o crescente futuro digital da economia na confluência de máquinas automatizadas, plataformas digitais e multidões. Já Srnicek (2017) descreve como característico do século XXI um "capitalismo de plataformas", no qual as plataformas digitais se apresentam como um modelo de negócio baseado na extração e análise de dados. $O$ autor observa que a economia digital está se tornando um modelo hegemônico, pelo qual o capitalismo procurou manter sua vitalidade e o crescimento econômico frente à estagnação do setor produtivo que se evidencia a partir dos anos 1970. Sua observação é de que as plataformas se configuram como um modelo de negócio que se liga diretamente às reestruturações pelas quais passou o capitalismo e que fizeram emergir novas tecnologias, formas de organização, modos de exploração, tipos de emprego e de mercado. Tudo isso se deu em resposta ao que define como crise de sobrecapacidade do setor industrial na década de 1970: as taxas de lucro decaíram de modo generalizado devido à alta capacidade produtiva das indústrias e estas precisaram recorrer à adoção de modelos de negócio lean e ao ataque ao poder da organização coletiva dos trabalhadores.

Nos anos 1990, os investidores, em busca de maiores taxas de retorno, migraram em massa para o setor das tecnologias da informação - por isso o fenômeno especulativo da "bolha da internet" nos Estados Unidos. Mesmo com o estouro da bolha em meados dos anos 2000, os massivos investimentos no setor de tecnologia da informação e de comunicação possibilitaram o desenvolvimento das infraestruturas técnicas que viriam sustentar a economia digital atual. Além disso, com a seguinte crise de 2008, ocasionada pela especulação no setor imobiliário naquele país, houve como resposta uma redução das taxas de juros promovida pelos principais bancos centrais do mundo, estabelecendo um ambiente global de baixas taxas de retorno sobre investimentos.

Como efeito mais evidente para os trabalhadores, Cantarella e Strozzi (2019) mostram, a partir de análise robusta de dados extraídos de surveys aplicados nos Estados Unidos e Europa, que 
trabalhadores de plataformas digitais recebem $70,6 \%$ menos se comparados a trabalhadores tradicionais com mesmo grau de habilidade e pelo mesmo tempo de serviço. $O$ estudo focou apenas em plataformas de "microtrabalho", nas quais os trabalhadores são remunerados por pequenas tarefas geralmente realizadas pelo clique do mouse, como a Amazon Mechanical Turk, Crowdflower, Clickworker e Microworkers.

Em perspectiva crítica, Huws (2014) examina como as tecnologias de informação possibilitaram novas áreas de acumulação do capital na cultura e nas artes, na privatização de serviços públicos e na mercantilização da sociabilidade humana por meio de plataformas digitais e de dispositivos móveis. Na sua visão, esse processo foi acompanhado por uma reestruturação dramática nos arranjos do trabalho que, no que lhe concerne, fizeram emergir novas contradições e novas formas de solidariedade e luta no trabalho em todo o planeta.

Corrobora essa visão o cenário teorizado por Zuboff (2019) de um "capitalismo de vigilância" (surveilllance capitalism), enredado no uso de plataformas digitais como o Google e o Facebook, detentoras de alta capacidade algorítmica, de predizer e controlar o comportamento humano. Segundo a autora, essa nova forma de organização da produção e de consumo se afasta da história do capitalismo de mercado ao tornar obsoleta a necessidade das empresas em estabelecerem reciprocidades orgânicas de longa duração com os trabalhadores, característica do fordismo, e ao fazer as pessoas se oporem a uma visão coletivista da sociedade.

Sundararajan (2016) também aportou estudos importantes para a compreensão do funcionamento das plataformas digitais e seu impacto sobre as hierarquias na organização da atividade. Nos últimos duzentos anos, ocorreu uma transição gradual da estrutura de mercado para a sofisticada e complexa estrutura de hierarquias das firmas e corporações. Contudo, o emprego das recentes tecnologias da informação potencializou, como efeito, uma tendência de crescimento horizontal das organizações, expandindo suas atividades econômicas para além das fronteiras 
geográficas tradicionais, reduzindo o crescimento vertical dessas empresas e achatando suas hierarquias administrativas.

Estudos citados por Sundararajan (2016) descrevem um cenário no qual empresas que passaram a utilizar tecnologias digitais apresentaram um ganho de produtividade, mas para isso também precisaram investir em uma série de mudanças organizacionais complementares, como o achatamento de hierarquias, o "empoderamento" de trabalhadores (aqui podemos entender aumento de responsabilidades e de autocontrole), a reformulação do trabalho e o aumento das formas de pagamento com base em desempenho. Soma-se ainda a essas mudanças organizacionais, o aumento das formas de terceirização possibilitadas por tecnologias digitais capazes de acessar uma multidão de prestadores de serviços. Nesse sentido, o autor classifica esse modelo de economia como um "capitalismo de multidões".

Sundararajan (2016) apresenta ainda um enquadramento de quatro plataformas (Airbnb, Uber, Etsy e TaskRabbit) com base em vinte e duas dimensões analíticas correspondentes aos aspectos estruturais do que chama de mercados puros, e das hierarquias corporativas tradicionais e das formas híbridas entre os dois. Elementos estruturais de mercados são, por exemplo, a possibilidade de os usuários escolherem livremente o preço pelo trabalho ou serviço praticado, de possuírem seus próprios instrumentos ou equipamentos, e a facilidade de entrar ou sair das relações estabelecidas por meio das plataformas. Exemplos de elementos estruturais das hierarquias são a centralização e controle da distribuição de serviços e da conexão entre trabalhadores e consumidores pela plataforma, o controle do processamento de pagamentos e a centralização dos serviços de atendimento ao consumidor. Foi possível ao pesquisador constatar que as quatro plataformas analisadas se configuram estruturalmente como híbridas, ou seja, agregam elementos tanto de mercados puros como das hierarquias corporativas tradicionais.

Também, problematizando a categorização de todas as plataformas sobre o mesmo rótulo de uma "economia do compartilha- 
mento", Sundararajan (2016) comenta brevemente o resultado da aplicação do mesmo enquadramento na análise de mais de cem plataformas. $\mathrm{O}$ autor chegou à conclusão de que muitas delas, de fato, se assemelham às características de mercado que facilitam o empreendedorismo, corroborando a ideia de uma "economia do compartilhamento" - como a plataforma de comércio Etsy e a de prestação de serviços manuais Upwork. No entanto, uma quantidade significativa apresentou mais semelhanças com as estruturas das firmas tradicionais, principalmente no que tange à contratação de prestadores de serviços (contractors) - como as plataformas de serviço Luxe, Postmate e Universal Avenue.

\section{"Uberização", subordinação, formas de solidariedade e resistência}

A denominada "uberizaçao", no sentido de trabalhos em forma de prestação de serviços, é entendida como um processo emergente no mundo do trabalho de ampliação do trabalho precário (SLEE, 2017; ANTUNES, 2018). Por outro lado, a inteligência artificial, o uso de Big Data e o gerenciamento por algoritmo já são uma realidade nos locais de trabalho e são ferramentas tecnológicas usadas para controlar, gerir e monitorar intensivamente os trabalhadores. Uma vasta literatura tem manifestado preocupação sobre a ampliação do controle do trabalho "uberizado" que, provocada pela forma como as empresas-plataformas utilizam a automação e o avanço tecnológico, cria enormes riscos à proteção do trabalho, aos direitos fundamentais e à dignidade humana nos postos de trabalho.

Em muitos sistemas jurídicos o controle e a subordinação são elementos-chave para definir a incidência da proteção pelo Direito do Trabalho, para usufruir dos direitos trabalhistas. Contudo, esses direitos funcionam como uma contrapartida pelos poderes de controle gerenciais exercidos pelo empregador, que também definem a sua responsabilidade pelo uso abusivo do gerencia- 
mento. Ocorre que os modelos de gerenciamento algorítmico das plataformas produzem, por um lado, um modelo de turvamento da noção de subordinação e controle, com simulação fraudulenta que mascara uma relação de trabalho e, por outro lado, tornam opaca e dispersa a responsabilização das plataformas dada a sua resistência ao reconhecimento da qualificação jurídica de assalariamento.

Diversas pesquisas empíricas em desenvolvimento apresentam os elementos mais concretos da organização do trabalho e dos mecanismos do processo de trabalho controlado por algoritmos. Em pesquisa recente realizada com entregadores ciclistas e motoboys de aplicativos, Ludmila Costhek Abílio (2019) constatou o impacto dos elementos da "uberização" no trabalho e vida desses trabalhadores. Esse processo de "uberização" é definido pela pesquisadora como uma nova forma de controle, gestão e organização do trabalho, que tem se difundido globalmente e se apresenta como uma tendência que elimina direitos e transforma os trabalhadores, de diferentes setores da economia, em gerentes de si mesmos. Isso ocorre devido a horizontalizaão das hierarquias de controle nas empresas contemporâneas, que perceberam o aumento de produtividade e corte de custos ao eliminarem cargos intermediários de gerência e passarem a responsabilidade de gestão do trabalho para o próprio trabalhador.

A "uberização", assim, apresenta-se como um processo "bem-sucedido em transformar o trabalhador em um trabalhador disponível ao trabalho, desprovido de direitos, que arca com custos e riscos e é remunerado na exata medida do que produz" (ABíLIO, 2019, p. 10). Mais ainda, ocorre uma transformação das narrativas de parte dos trabalhadores, que em um primeiro momento enalteciam o caráter de empreendedorismo do trabalho mediado por plataformas digitais, mas que passou a ser percebido, após a crescente concorrência causada pela adesão de uma multidão de trabalhadores a uma mesma plataforma e consequente redução dos rendimentos, em uma forma de autogerenciamento subordinado (ABÍLIO, 2019). 
Como exemplo de exercício turvo de controle, Abílio (2019) identifica uma prática utilizada pelas empresas de entrega por aplicativos para intensificar e aumentar o número de deslocamentos realizados pelos entregadores. Trata-se de uma "gamificação" do trabalho, a qual estipula metas e prêmios em dinheiro caso essas sejam atendidas em um determinado tempo, tal como em um jogo. O relato de um entregador colhido pela pesquisadora explica a prática: “[...] se o tempo estiver chuvoso, igual hoje de manhã, eles mandam mensagem às 9 horas: das $10 \mathrm{~h}$ até as $13 \mathrm{~h}$, fazendo oito pedidos delivery, você ganha mais $\mathrm{R} \$ 50$. Se você não fizer, você não ganha o bônus".

Em linhas gerais, constata-se que o gerenciamento e o controle algorítmico, uma das principais características do trabalho em plataformas, traz a possibilidade de mapear e ordenar eficientemente a atividade de uma multidão de trabalhadores. Porém, as batalhas judiciais travadas contra as plataformas têm como um de seus pontos fracos a insuficiente compreensão da reconfiguração da natureza do vínculo de emprego pelas plataformas.

Uma decisão recente do judiciário brasileiro indica a tendência à invisibilidade dessas novas formas de subordinação a que estão submetidos os trabalhadores de plataformas digitais. A Segunda Seção do Superior Tribunal de Justiça (STJ), em decisão sobre conflito de competência, publicada em 4 de setembro de 2019, entendeu, com unanimidade de seus dez ministros, que os motoristas da Uber não possuem vínculo de emprego e que por isso devem pleitear seus direitos na esfera da justiça comum e não na justiça do trabalho. O ministro relator Moura Ribeiro afirmou: "Afastada a relação de emprego, tem-se que o sistema de transporte privado individual, a partir de provedores de rede de compartilhamento, detém natureza de cunho civil" (BRASIL, 2019).

Quanto ao enquadramento em relação aos critérios que estabelecem vínculo de emprego, a decisão entendeu que: "Os motoristas de aplicativo não mantêm relação hierárquica com a empresa Uber porque seus serviços são prestados de forma eventual, sem horários pré-estabelecidos, e não recebem salário fixo, o que des- 
caracteriza o vínculo empregatício entre as partes" (BRASIL, 2019). O relator, assim, concluiu sobre a natureza do trabalho realizado: "Nesse processo, os motoristas, executores da atividade, atuam como empreendedores individuais, sem vínculo de emprego com a empresa proprietária da plataforma" (BRASIL, 2019). Com isso, sendo o litígio nesse processo derivado de relação jurídica de cunho eminentemente civil, sua competência foi atribuída à Justiça Estadual.

A decisão do STJ evidencia o caráter decisório dos magistrados brasileiros em relação à "uberização" do trabalho. Por um lado, partem do princípio da primazia da realidade e reconhecem as novidades tecnológicas, as novas formas de trabalhar e de organizar o trabalho nas justificações de suas decisões. Por outro lado, a tendência é de não reconhecerem as "transformações dos padrões clássicos da dependência e subordinação" ${ }^{1}$ (MACHADO, 2019, p. 81).

Em relação à reconfiguração dos conflitos que envolvem 0 trabalho em plataformas digitais, o pesquisador do Oxford Internet Institute, instituto da Universidade de Oxford, Vili Lehdonvirta (2016), em um aprofundado estudo sobre plataformas de microtrabalho (microwork), argumenta que, devido à dispersão de papéis e de identidades, não fica claro em que medida continua a fazer sentido abordar esse mercado de trabalho utilizando um modelo binário, no qual trabalhadores e capitalistas lutam pela alocação dos rendimentos provenientes de seus respectivos fatores na produção. Assim, propõe que, nas análises do trabalho disperso e fragmentado, talvez seja o caso de adotarmos a perspectiva de Castells (1996). Este sociólogo espanhol sugeriu que, no setor informacional, o conflito binário entre capital e trabalho foi substituído por uma "economia em rede", configurada em uma "geometria variável" de atores individuais, constantemente incluídos ou excluídos com base nas suas possibilidades de contribuição. Segundo Castells, interpretado por Lehdovirta (2016), ao invés de um conflito binário, essa "economia em rede" dispõe de

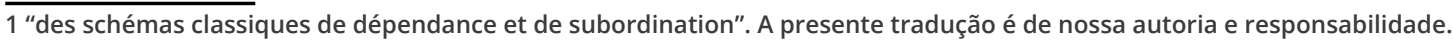


complexos e variados padrões de diferenciação, colaboração e de exploração, cada um desses necessitando de análises próprias.

Nesse sentido, quanto aos padrões de colaboração emergentes, Sundararajan (2016) insere a discussão sobre solidariedades nas plataformas digitais na interação de duas formas de economia, a economia de mercado (market economy) e a economia da dádiva (gift economy). A primeira diz respeito às trocas comerciais valoradas por dinheiro, já a última produz valor sem a mediação do dinheiro. No seu entendimento, o "capitalismo de multidão" engloba formas híbridas desses dois tipos de economia. O autor cita como exemplo as plataformas de acomodação Couchsurfing, Airbnb e OneFineStay: a primeira plataforma compreende a criação de vínculos comunitários e de uma rede social de reputação e confiança que possibilita pessoas de todo o mundo se hospedarem gratuitamente na casa de estranhos; já o Airbnb seria uma forma híbrida intermediária, reunindo elementos da economia de mercado, ou seja, o pagamento pelas acomodações, mas também elementos da economia da dádiva, pois hóspedes e hospedeiros frequentemente estabelecem vínculos para além da relação comercial; já a plataforma inglesa OneFineStay apenas aluga casas de alto padrão sem o contato entre proprietários e hóspedes.

Esse esquema de classificação também permite ao autor situar as plataformas de financiamento coletivo e as plataformas de prestação de serviços (service platforms), esta última de maior interesse para o campo de estudos do trabalho. Como exemplo, localiza as seguintes plataformas ao longo do espectro que vai da economia da dádiva à economia de mercado: Trade School, na qual pessoas dão aulas entre si sem o intermédio de dinheiro; TimesFree, na qual pessoas prestam serviços umas as outras tendo como base da troca apenas a quantidade de tempo despendido em cada serviço; e, por fim, as plataformas TaskRabbit e Handy, que funcionam como um mercado de trabalho em que pessoas são pagas por tarefas ou pelas horas trabalhadas sem necessariamente a criação de laços de comunidade característicos da economia da dádiva, tendo como princípio o manejo de tempo de trabalho ocioso, possível de ser acionado em rede. 
Com base nessa variedade e diversidade de modelos de compartilhamento e de serviços que são abarcados pelo "capitalismo de multidão", Sundararajan (2016) observa o surgimento de um modelo econômico híbrido situado entre o socialismo e o capitalismo, capaz de atender às necessidades e características das pessoas que se identificam com um ou outro desses dois extremos e, talvez mais importante, citando Durkheim, capaz de recriar contextos sociais de solidariedade outrora destruídos pela Revolução Industrial.

No entanto, um contexto atual de crise das solidariedades, de crescente individualismo e de desigualdade social é descrito por Dubet $(2014 ; 2018)$, que defende a necessidade de se imaginar novas formas de solidariedade. Azaïs, Dieuaide e Kesselman (2017) sugerem a mobilização da noção de "zona cinzenta" de regulação do trabalho para ilustrar casos como o da plataforma Uber e também como um modo diferenciado de captar, em um contexto de globalização e de nova cartografia do poder, as transformações na relação de emprego e a emergência de uma variedade de novas formas de subordinação e de reação por parte dos trabalhadores. Dentre essas formas, os autores identificam: mover as fronteiras entre o público e o privado; utilizar a capacidade de organização numérica contra as próprias empresas; contestação política e denúncia das práticas das empresas na sociedade civil.

Algumas experiências de mobilização e organização dos trabalhadores de plataformas foram descritas pelo informe da OIT (2019). Como exemplo de solidariedade entre sindicatos tradicionais e trabalhadores em plataformas situa-se a FairCrowdWork. org, criada em 2015 pela IG Metall, sindicato dos metalúrgicos da Alemanha, pela Arbeiterkammer da Áustria, pelo sindicato Unionen da Suécia e pela Confederação Austríaca de Sindicatos. Esse tipo de ação tem como propósito fornecer informações, sob uma perspectiva sindical, sobre as plataformas digitais. Disponibiliza também informações sobre direitos e obrigações legais dos trabalhadores inseridos nessas plataformas e oferece descrições dos processos de trabalho e uma classificação de qualidade de diversas plataformas. 
No seu livro mais recente, Uberização, trabalho digital e Indústria 4.0 (2020), Ricardo Antunes analisa o "quadro social crítico" brasileiro e reflete sobre os impactos da pandemia global da Covid-19. O autor enfatiza uma tendência destrutiva em relação ao trabalho, levada a cabo pela lógica das plataformas digitais. Sua constatação é de que se essa tendência não for "fortemente confrontada, recusada e obstada, sob todas as formas possíveis" (ANTUNES, 2020, p. 15), se acentuará a crise do quadro social por meio da expansão de formas ocultas de assalariamento do trabalho, mas intrinsecamente desprotegidas, uma vez que apresenta os trabalhadores como "autônomos" e "empreendedores". Nesse sentido, na leitura que faz do "campo de lutas", o autor observa o "advento de um novo proletariado de serviços" como sendo a mais importante consequência da tendência destrutiva constatada. Ou seja, aponta para o nascimento de "novas formas de representação". No cerne de seu argumento está o reconhecimento de que há uma "nova morfologia do trabalho", complexa e fragmentada, a qual demanda do "novo proletariado" a capacidade de "ressoldar" os "laços de pertencimento de classe". Essa classe, na visão de Antunes (2020), configura-se de modo segmentada, heterogênea, clivada por gênero, raça e etnia, tudo isso produzindo consequências em como age concretamente e em como se representa.

Por tudo isso e como tentativa de compreensão do agravamento, com a atual pandemia, do já crítico e "dilacerado" quadro social brasileiro, Antunes (2020) formula três hipóteses analíticas para o futuro - e todas elas se voltam para a questão das plataformas digitais. A primeira é a de o trabalho "uberizado", vigente nas plataformas digitais, constituir o principal campo de experimentação do capital para impulsionar suas cadeias produtivas globais, pelas quais ocorre o cerne do processo de criação de valor e de riqueza social, e que se traduz na crescente imbricação do trabalho humano com tecnologias de informação e comunicação (TIC). De modo concreto, segundo o sociólogo, as plataformas digitais estão generalizando e se utilizando cada vez mais dos traços característicos do trabalho do Sul global: a informalidade, a flexibilidade e a 
precarização. Essas empresas se valem de algoritmos, inteligência artificial e outros dispositivos digitais para expandirem seus lucros, o que resulta na criação de novas modalidades de trabalho caracterizadas por jornadas extensas, baixos salários e demissões repentinas e injustificadas.

Em decorrência desse cenário de destruição em relação ao trabalho, marcado por "mais informalização com informatização", Antunes (2020) formula como segunda hipótese a constatação de que a ampliação global das formas de exploração do trabalho, em pleno "capitalismo de plataforma", remete às características do início da Revolução Industrial, àquilo que denomina de "protoforma do capitalismo" e à sua fase de acumulação primitiva: jornadas de trabalho superiores a oito horas, baixa remuneração, aumento da intensificação do trabalho e crescimento do contingente de pessoas sem acesso a direitos sociais e trabalhistas. A partir disso decorre sua terceira hipótese, de que "estamos ingressando em uma nova fase de desantropomorfização do trabalho" (ANTUNES, 2020, p. 21), marcada pela "intensificação da subsunção real do trabalho à nova máquina-ferramenta-informacional" (ANTUNES, 2020, p. 22). Com isso, a "nova fase digital, algorítmica e financeira" do mundo corporativo atual impõe e reforça novas modalidades de trabalho "uberizado", o que por sua vez dificulta as ações coletivas e a resistência sindical. No entanto, de modo otimista, por consequência da terceira hipótese, o autor entende que a "nova morfologia do trabalho" abre espaço para a emergência de uma "nova morfologia das lutas sociais".

Nesse âmbito, formas emergentes de solidariedade e resistência manifestam-se em racionalidades e narrativas capazes de contraporem os discursos que justificam as modalidades ocultas de subordinação e controle. Uma sociologia cultural voltada ao âmbito do trabalho é empreendida e problematizada por Lima (2010). Na sua definição, a cultura do trabalho é composta por estratégias e práticas que se entrelaçam e, por vezes, confundem-se com o que se entende por cultura de classe, cultura do capitalismo, cultura do assalariamento, cultura empreendedora etc., as quais 
têm em comum o trabalho como um elemento configurador das relações entre os atores. Segundo o autor, a cultura do trabalho é, assim, composta por ideologias justificadoras e contra-ideologias que ressignificam o mundo do trabalho em novas formas de consentimento ou de resistência, em novas formas de individualização ou de valorização da coletividade, e em novas proposições e interpretações das possibilidades da organização coletiva do trabalho e de explicação do social.

\section{Materiais e métodos}

A coleta e análise de dados para a realização da pesquisa ocorreram em duas etapas distintas e compreenderam metodologias diferentes. A primeira etapa de coleta de dados se deu com a distribuição de questionários (surveys) formulados pelo grupo de professores e pesquisadores da Rede de Estudo e de Monitoramento da Reforma Trabalhista (REMIR), que teve o objetivo de medir os impactos causados pela pandemia da Covid-19 no trabalho de entregadores por aplicativos. Foram obtidas respostas de 252 trabalhadores, de 26 cidades brasileiras, entre os dias 13 e 20 de abril. Realizamos, para este relatório, uma análise quantitativa paralela àquela publicada pelos pesquisadores da REMIR (ABÍLIO et al., 2020), utilizando os dados brutos provenientes da aplicação dos questionários. O objetivo foi quantificar a variação nos rendimentos e no tempo de trabalho dos entregadores por aplicativos, causada pelas mudanças sociais e econômicas introduzidas pela pandemia da Covid-19. Foram calculados e gerados os gráficos contendo a curva de distribuição normal e o desvio padrão respectivo, com os valores dos rendimentos semanais em reais e a jornada de trabalho diária em horas, referentes aos períodos de antes e durante a pandemia. ${ }^{2}$

$\mathrm{Na}$ segunda etapa, decidimos por um aprofundamento qualitativo da pesquisa, frente às recentes manifestações e paralisações

2 Utilizamos, no cálculo e geração dos gráficos, a linguagem de programação Python e as bibliotecas scipy, matplotlib e numpy. 
realizadas pelos trabalhadores compreendidos neste estudo, sendo que um dos fatores principais das mobilizações apontava para a redução da remuneração e aumento da jornada de trabalho, dados constatados na análise quantitativa realizada previamente. Assim, optamos pela realização remota de um grupo focal, por meio de ferramenta de videoconferências, devido à necessidade de isolamento social. A técnica dos grupos focais potencializa a investigação de processos de influência grupal, de crenças, valores, atitudes e opiniões, possibilitando a geração e construção de hipóteses, teorias e instrumentos de análise, bem como o aprofundamento do conhecimento sobre um tema específico. Por meio dessa metodologia de pesquisa e de coleta de dados, os entrevistadores desempenham o papel de moderação e de facilitadores do processo de discussão, atentando-se para o jogo de influências e para a emergência e formação de opiniões sobre o tema problematizado. Consequentemente, define-se e parte-se do grupo como unidade de análise e de interpretação (GONDIN, 2003).

No caso desta pesquisa, o grupo focal teve o formato de uma roda de conversas, com o objetivo de coletar as opiniões e entendimentos de lideranças e trabalhadores de aplicativos de entregas da cidade de Curitiba. Estiveram presentes 4 entregadores motoboys, 1 entregador biker e 1 vereador e sindicalista. Sua duração foi de duas horas, sendo posteriormente transcrita para a análise textual de seu conteúdo. Previamente à realização do grupo focal, que ocorreu no dia 23 de julho de 2020, elaboramos um roteiro de perguntas em torno de duas temáticas: remuneração/jornada de trabalho; e mobilizações e greves dos entregadores de aplicativos que ocorreram em todo Brasil, no dia primeiro de julho de 2020, e uma segunda onda de manifestações que estava agendada para acontecer no dia 25 de julho de 2020.

Juntamente à análise e descrição das discussões ocorridas durante o grupo focal, optamos por fazer uma análise qualitativa por meio de software do conteúdo textual do grupo focal, a qual permite a visualização gráfica do enquadramento contextual dos assuntos centrais à discussão. 
Para tanto, foi utilizado o pacote de software aberto KH Coder (HIGUCHI, 2020) que reúne diferentes métodos e ferramentas de análise e visualização de conteúdo textual. Partimos do entendimento de que a análise de redes e suas representações gráficas são uma ferramenta proeminente na sociologia (DEGENNE; FORSE, 1999; PFEFFER, 2008 citados por HAMANN; SUCKERT, 2018). O método e a ferramenta escolhidos foram as de visualização em redes de coocorrência de palavras (co-ocurrence networks of words). O software utiliza o método computacional desenvolvido por Fuchterman e Reingold (1991) para a diagramação da rede de palavras como uma rede de coocorrências.

Nesse tipo de rede, composta por nós e linhas, as palavras compõem os nós, e suas relações de coocorrência entre as respostas de cada respondente compõem as linhas que conectam os nós. Assim, os diagramas mostram as palavras que apresentam um padrão similar de aparição nas respostas. Outra funcionalidade analítica que a ferramenta fornece, e aqui utilizada, é o cálculo da centralidade de intermediação (FREEMAN, 1977) de cada palavra em relação à rede, fazendo variar a coloração da palavra no diagrama, sendo mais azuis aquelas que representam maior centralidade (centrality). A frequência (frequency) de cada palavra mencionada pelos respondentes também é representada nos diagramas pelo tamanho do círculo de cada nó/palavra (HIGUCHI, 2016).

Realizamos o recorte e a separação da transcrição do grupo focal em dois arquivos de texto de acordo com as duas temáticas discutidas: remuneração/jornada e mobilizações/paralisações. Assim, procedemos com o pré-processamento dos arquivos de texto no software KH Coder para a posterior diagramação das redes de coocorrência de palavras. Para cada diagramação, limitamos às palavras com o mínimo de cinco menções. Selecionamos para que apenas os substantivos fossem processados e, com isso, buscamos possibilitar o agrupamento de palavras com significados semelhantes, o que por sua vez permite a análise léxica e semântica das palavras no seu contexto. A análise léxica se apresenta como uma ferramenta ideal para a exploração de respostas às perguntas abertas, possibilitando 
O trabalho em plataformas digitais: direitos, covid-19 e problemas emergentes Sidnei Machado • Alexandre Pilan Zanoni

\section{Gráfico 1 - Rendimento semanal antes e durante a pandemia (2020)}

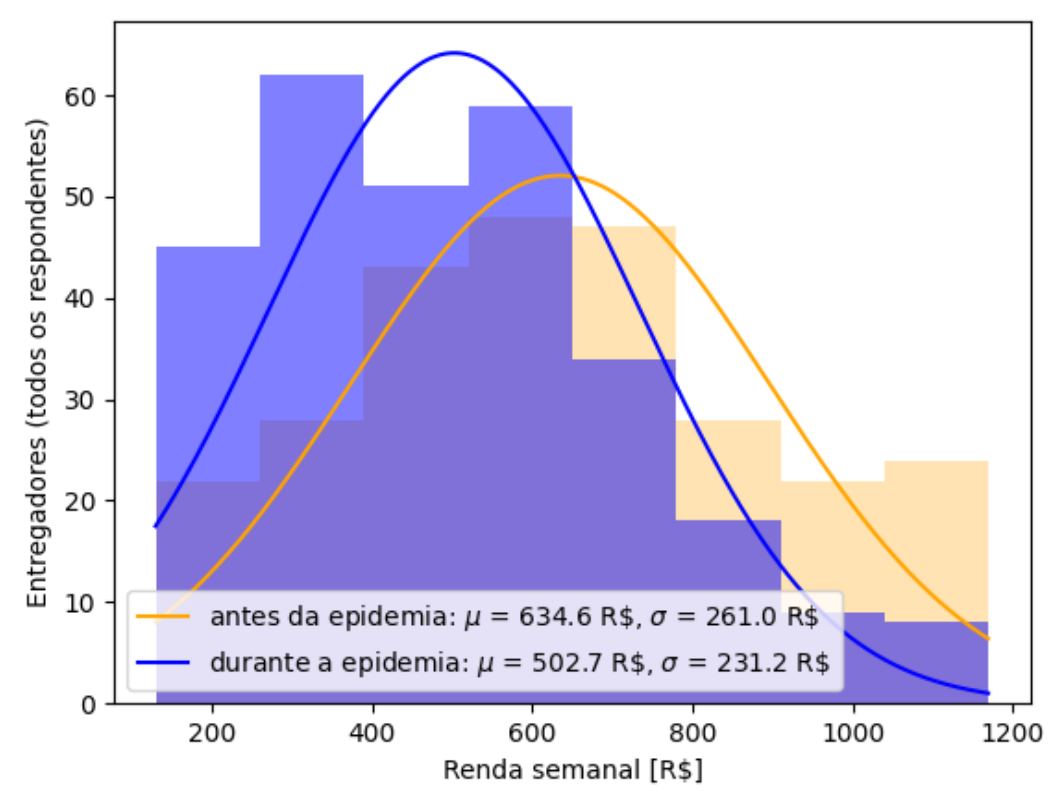

Fonte: Elaborado pelos autores a partir do Banco de dados da pesquisa da REMIR (ABÍLIO et al., 2020).

\section{1}

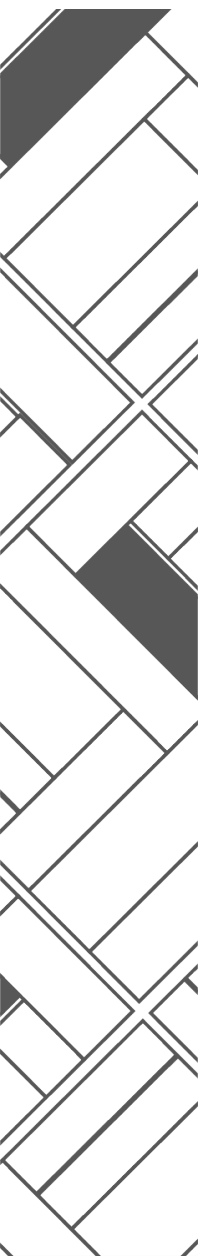

Quanto ao tempo de trabalho, houve uma inexpressiva variação na jornada média, de aproximadamente 10 horas diárias (Gráfico 2). Portanto, a partir dessa amostra, constata-se que houve uma redução no valor remunerado da hora trabalhada. É importante salientar que o questionário teve como enfoque a população de entregadores que atuam exclusivamente nos aplicativos. 


\section{Gráfico 2 - Jornada diária antes e durante a pandemia (2020)}

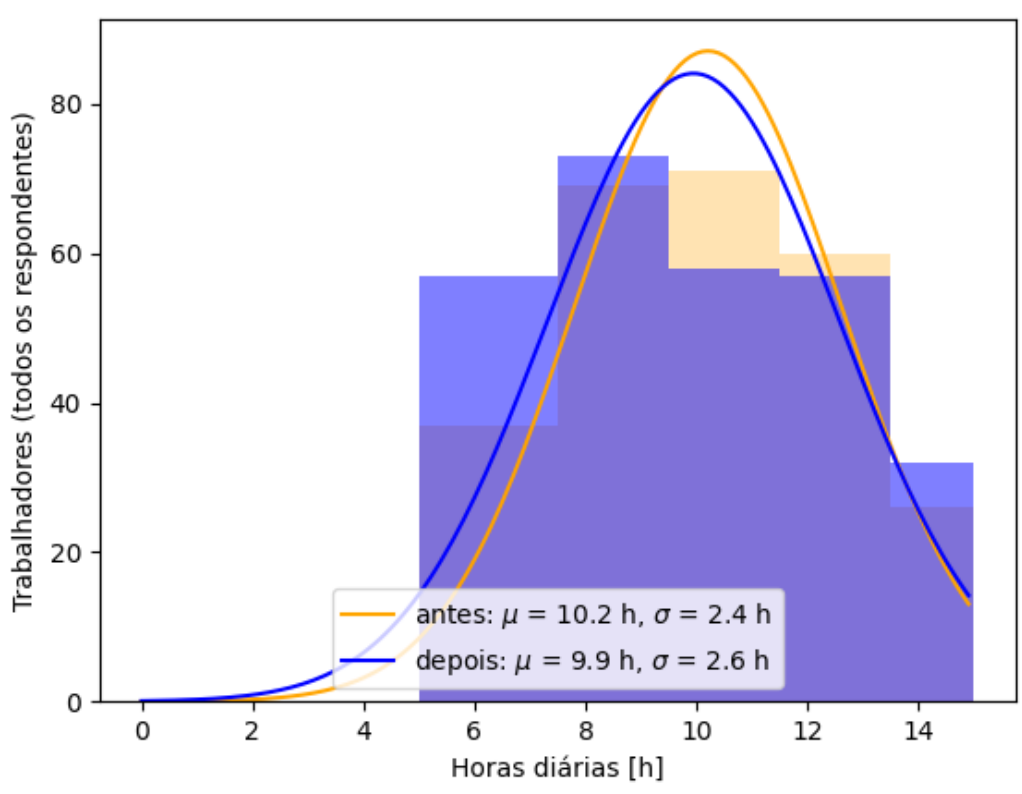

Fonte: Elaborado pelos autores a partir do Banco de dados da pesquisa da REMIR (ABÍLIO et al., 2020).

\section{2}

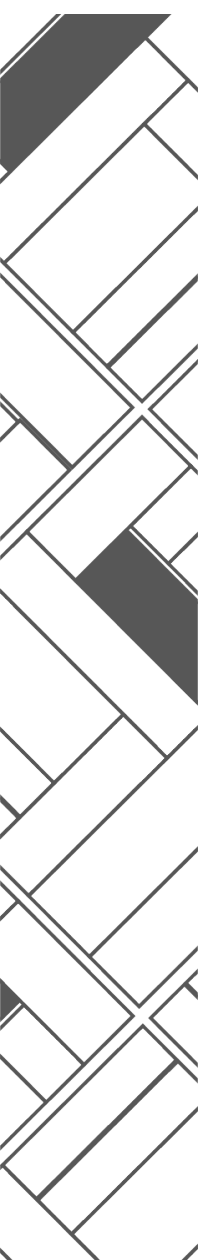

Uma das possíveis explicações para a redução nos rendimentos semanais dos entregadores via aplicativos está no crescimento do número de entregadores disponíveis nas diferentes plataformas (ABÍLIO et al., 2020), fenômeno causado pelo aumento do desemprego no período da pandemia, que encontraram nessas plataformas a única alternativa para obtenção de renda. Outra explicação está no oportunismo das empresas, que observaram crescer a demanda e a dependência das pessoas e da sociedade em isolamento social pelos serviços de entrega. Mais pesquisas precisam ser feitas para precisar a causalidade por trás da redução da remuneração dos entregadores.

De qualquer modo, no dia primeiro de julho de 2020 ocorreram manifestações e paralisações dos entregadores por aplicativos em diferentes cidades do país, movimento que ficou conhecido como "Breque dos APPs", ou seja, um freio (brake) nos aplicativos, utilizando a linguagem corrente dos motoboys. Entre as reivindicações por parte dos entregadores, constaram: o aumento do valor 
por quilômetro rodado; aumento do valor mínimo por entrega; fim dos bloqueios e desligamentos indevidos; seguro de roubo; seguro acidente e seguro de vida; fim do sistema de pontuação; auxílio financeiro durante a pandemia e materiais de prevenção ao coronavírus (como álcool-gel, máscaras, higienização das bags).

Conforme Machado (2020), a mobilização do dia primeiro de julho evidenciou a horizontalidade do movimento, sendo que suas articulações se deram na mesma lógica das plataformas e pelo uso massivo das redes sociais (Facebook, Twitter, Instagram e grupos de WhatsApp). Foi observado ainda o apoio e suporte na organização do movimento por centrais sindicais e sindicatos de classe, agregando nos protestos trabalhadores do setor formal de entregadores. Também foi identificada, nessa estratégia, uma articulação nova e emergente, ou seja, uma formação de solidariedade na luta por direitos dos trabalhadores. Esta inclusive se expressou na adesão e solidariedade de consumidores dos serviços ofertados pelos aplicativos, que manifestaram seu apoio por meio de avaliações negativas às plataformas. Tudo isso, somada à cobertura positiva do movimento pela grande mídia, ajudou a significar a greve como legítima e necessária.

No dia 25 de julho uma nova paralisação foi agendada pelo movimento "Breque dos Apps". Um informe digital produzido pelo perfil "tretanotrampo" (Facebook) circulou nas redes com o objetivo de desfazer o entendimento por parte de alguns entregadores de que o propósito das paralisações era para que todos "virassem CLT", enfatizando que: "a luta é para ganhar mais, não pra virar CLT ou placa vermelha e acabar ganhando menos. Ninguém aqui quer cumprir hora e ter chefe. Se vier regulamentação, a gente derruba!" (Figura 1). 
Figura 1 - Informe digital \#brequedosapps

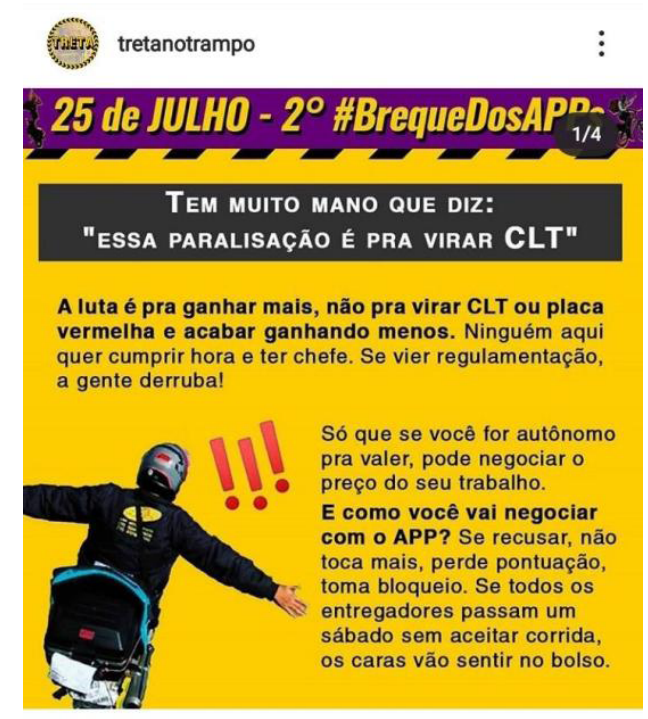

Fonte: Perfil "tretanotrampo" na rede social Facebook.

Observa-se, a partir desse informe, um esforço pela despolitização e desvinculação do movimento a sindicatos e à figura jurídica do vínculo de emprego formal. O movimento enfatiza que seu interesse principal é pelo aumento das "taxas", ou seja, o valor que recebem por cada entrega realizada. Entende, assim, que é possível conseguir, por meio das paralisações, causar prejuízos às plataformas de entrega e com isso obter algum poder de negociação. Sua pauta primeira, portanto, é por "taxas justas". Há, notadamente, uma ambiguidade no informe quanto ao conteúdo e ao sentido das duas paralisações. O que explica um movimento contrário à CLT?

No sentido de melhor compreender o entendimento dos entregadores de aplicativos e das lideranças locais da cidade de Curitiba, realizamos um grupo focal, no dia 23 de julho, no qual foram discutidas a remuneração/tempo de trabalho e a opinião dos participantes sobre a paralisação do dia primeiro e a então agendada para o dia 25 de julho. É importante salientar que a paralisação "Breque dos Apps" "não deu certo" em Curitiba, utilizando a expressão de um dos participantes, haja vista a baixa adesão dos entregadores, justificada em consenso tanto pela descrença 
de que a situação possa melhorar frente a grande quantidade de desempregados e da crise econômica, quanto pelo medo de sofrerem bloqueios e represálias por parte dos aplicativos.

Dos quatro motoboys que participaram do grupo focal, todos já estão há mais de cinco anos exercendo a atividade. Um deles está há dezesseis anos. Todos mesclam às entregas realizadas pelos aplicativos vínculos de emprego formal, ou prestação como autônomos regularizados, ou ainda atuação como informais. Portanto, nenhum deles informou depender exclusivamente das plataformas de entrega. Outro participante, entregador biker, depende unicamente das plataformas. Todos relataram possuir cadastro ativo em mais de um aplicativo. Por fim, o único participante que não está atuando como entregador é sindicalista e atualmente vereador no município de Curitiba, representante da categoria dos motofrentistas. Frisamos a particularidade e a configuração local do trabalho dos entregadores e motoboys da cidade de Curitiba, não sendo possível, sem estudos aprofundados, extrapolar as análises que seguem para a realidade nacional.

\section{5}

A discussão no grupo focal se iniciou com a pergunta aberta sobre o valor das taxas e como estava a situação da remuneração. Houve consenso que o valor atualmente praticado por entrega é "injusto", muito abaixo do que costumava ser alguns anos atrás. Relataram haver uma prática generalizada entre os motoboys da cidade de Curitiba de trabalharem em média 16 horas por dia. Todos eles confirmaram haver uma meta diária a ser alcançada, que gira em torno do valor de $\mathrm{R} \$ 200,00$ reais. Em cima desse valor fazem o cálculo dos custos da moto e do combustível, tentando chegar a um valor aproximado do quilômetro rodado, que atualmente estimam estar na faixa de $R \$ 1,00$.

Foram centrais na discussão o baixo valor ofertado pelas entregas realizadas e o elevado tempo de trabalho (Diagrama 1). Os participantes explicaram que as plataformas digitais pontuam positivamente o entregador, com um escore numérico, quanto mais ficar disponível na plataforma, "logado", e quantas entregas a mais for capaz de realizar em menos tempo. Sentem-se, assim, 
constrangidos a manterem uma rotina diária, sem que haja muitos períodos ou dias de interrupção, haja vista a possibilidade concreta de serem desligados das plataformas. Associam-se ao ritmo acelerado das entregas e às longas jornadas o elevado risco de acidentes. Entendem que na ausência de um salário fixo, é preciso estar disponível o maior tempo possível para cumprir a meta diária estabelecida. Costumam ligar seus aplicativos a partir das 10 horas da manhã, isso quando já não cumpriram meio expediente pela manhã em alguma empresa na condição de celetistas (trabalhador no regime da CLT). Frequentemente, avançam até a meia-noite ou duas horas da manhã, até a meta ter sido atingida. Segundo um dos participantes, há "aluguel e contas para pagar", por isso trabalha-se 16 horas por dia, de 6 a 7 dias por semana.

\section{Diagrama 1 - Grupo focal - Temática remuneração/jornada de trabalho (rede de coocorrência de palavras)}

\section{6}

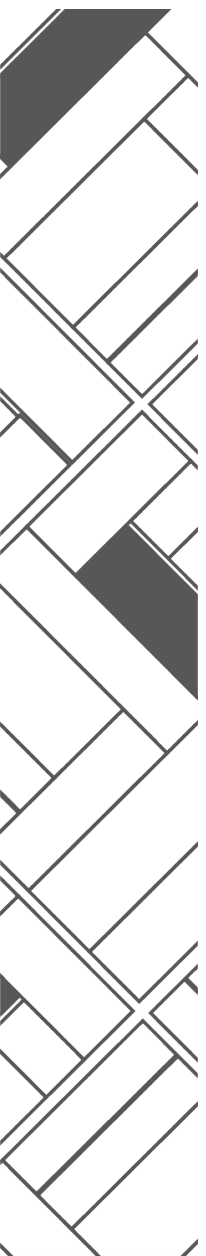

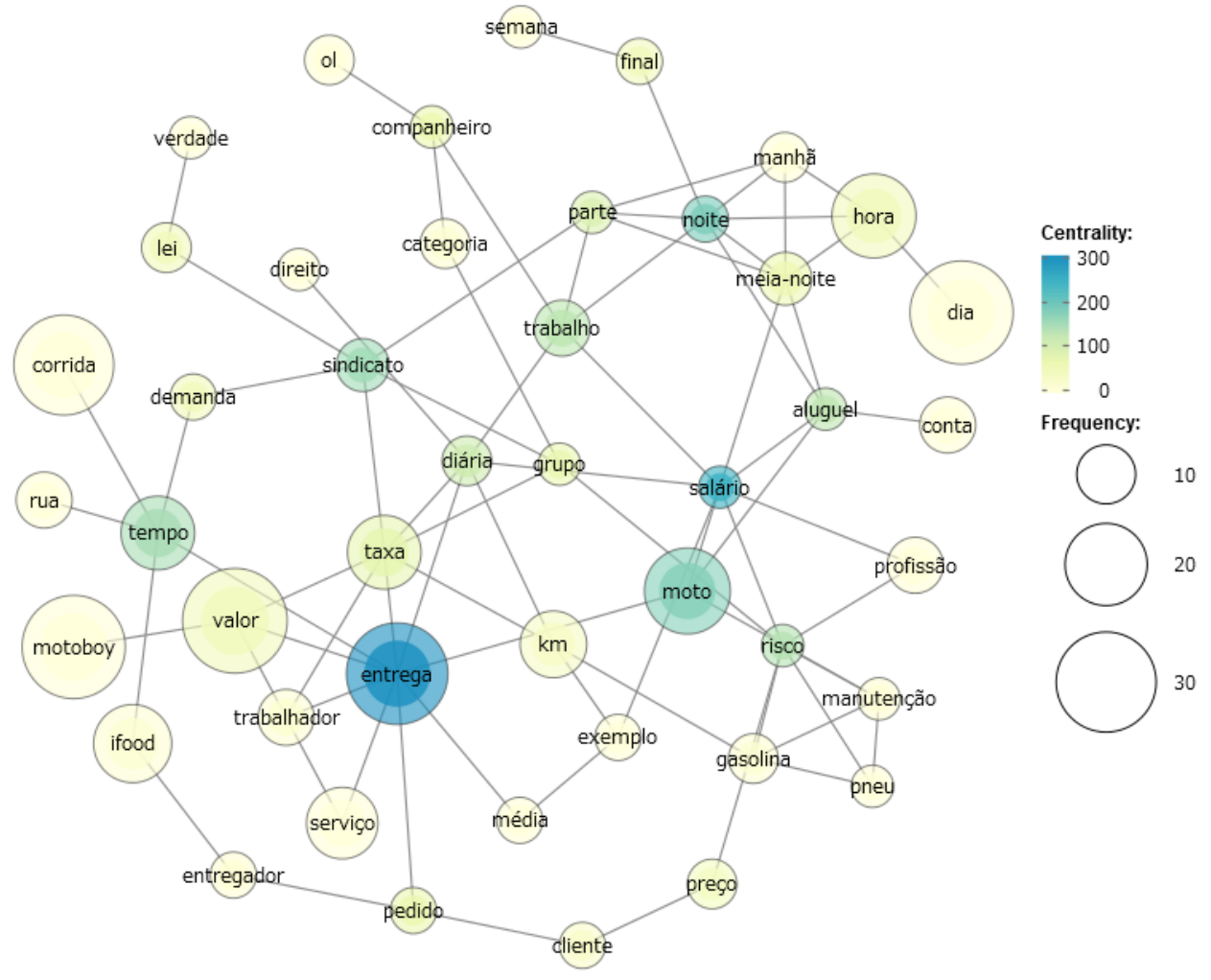

Fonte: Elaborado pelos autores (2020). 
do entendimento comum dos participantes de que o aumento de entregadores disponíveis nas plataformas ameaça todas as outras formas de vínculo e de contratação, pois as empresas (clientes) estão cada vez mais optando por utilizar as plataformas devido aos baixos preços praticados.

Como é possível visualizar (Diagrama 2), a discussão centrou-se na questão da profissionalização da categoria, na necessidade de regulamentação e controle da demanda e acesso ao mercado de trabalho dos entregadores, no sentido de melhorar as condições de remuneração por cada entrega realizada e de proteção à vida e de segurança frente aos riscos inerentes à profissão.

Como hipótese de interpretação dos dados coletados, compreendemos ser consenso entre os participantes do grupo focal a necessidade da construção e da valorização de uma identidade do tipo profissional, à qual eles se autorreferem como mobotoys ou motofrentistas.

Perkin (2002) constrói a história da emergência do profissionalismo como um modelo, ou seja, como uma forma pela qual as sociedades se organizam para atender a certa classe ou interesse e também como um ideal de cidadão, cuja subjetividade se firma a partir da experiência obtida por treinamento especializado e na seleção por mérito. Para o historiador, as condições profissionais de trabalho (professional conditions of work) têm se expandido e atravessado as fronteiras do trabalho não-manual, atingindo cada vez mais trabalhadores da "classe trabalhadora manual".

Gonçalves (2006) resume a racionalidade e as estratégias de mercado do profissionalismo:

Ùm dos objectivos dos grupos profissionais é estabelecer, por intermédio da autorização estatal, o seu fechamento social baseado fundamentalmente na monopolização de segmentos dos mercados de trabalho e no credencialismo. Monopolização que necessariamente confere aos grupos um conjunto de privilégios materiais e simbólicos superiores aos das ocupações em geral. (GONÇALVES, 2006, p. 27). 
Nesse sentido, são possíveis de serem listados ao menos quatro fatores para a formação do consenso em torno da importância de firmarem a respectiva identidade profissional de motoboys.

O primeiro fator é o conhecimento comum de que a atividade envolve riscos e que requer um conhecimento especializado; o corolário deste é a noção compartilhada de que entregadores jovens, sem experiência, se acidentam mais. Há, ainda, o impasse em chamá-los pelos mesmos nomes que indicam o profissionalismo do motoboy ou do motofrentista. São "rapazes" e "meninos" que estão "prostituindo" a profissão ao aceitarem realizar entregas por qualquer valor e de qualquer modo.

O segundo elemento são os valores de autonomia e liberdade frequentemente acionados para justificar a hibridez nas formas que estabelecem seus vínculos com empresas, plataformas e/ ou clientes avulsos. Há uma economia difusa que necessita dos serviços de entrega, apresentando uma amplitude da temporalidade na qual é possível estar em atividade. Nesse sentido, indicam haver uma racionalidade comum, entre os motoboys, na programação de suas jornadas de trabalho, cientes dos horários de maior demanda do setor alimentício (almoço e jantar). Entendem, então, que não seria vantajoso, de acordo com a racionalidade que visa à maximização da quantidade de entregas em função da temporalidade específica das diferentes economias nas quais se inserem, que houvesse uma luta política pela padronização das suas atividades como apenas celetista. Ou seja, indicam, pelo consenso formado no grupo focal, de que é mais vantajoso poder contar tanto com um vínculo celetista, por meio período, como no mesmo dia poder contar com a possibilidade de trabalhar para plataformas, prestar serviços como autônomo regulamentado ou até mesmo informalmente. A partir dessa racionalidade é possível compreender as pautas presentes nas mobilizações ocorridas em julho de 2020, sendo que nenhuma delas tocava no ponto do reconhecimento de vínculo empregatício com as plataformas.

O terceiro fator é o de que eles compartilham do entendimento de haver a necessidade de uma regulamentação específica para 
que se possa exercer a atividade de motofrentista legalmente, independentemente da forma do vínculo/contrato de serviço. Nesse sentido, apresentam uma evidente racionalidade profissional de fechamento e controle no acesso a esse mercado de trabalho (PARADEISE, 1988). Assim, não são contrários à atuação das plataformas, já que veem nelas mais uma oportunidade de permanecerem em atividade, mas sim à permissibilidade em que admitem novos entregadores. Entendem que se houvesse a efetiva atuação do Estado na fiscalização e na regulamentação da atividade, o acesso à profissão seria limitado, solucionando o principal problema identificado pelos participantes do grupo focal, qual seja, os valores "injustos" das taxas de entrega. O sentido de justiça evocado, portanto, atrela-se a uma racionalidade do tipo profissional, de mercado, consciente e calculadora das variações de oferta e de demanda. De fato, indicam pensar e agir com a mesma mentalidade das plataformas, pois a justificam e dizem compreendê-la. Por esse viés, são descrentes quanto aos efeitos das greves e paralisações recentes.

Por último, aparece a forma da solidariedade do tipo profissional, avessa à intermediações e a uma verticalidade nas representações políticas. Também, parece haver um reiterado uso e uma forma de pensamento religiosa do tipo protestante, no uso das expressões e ressignificações que fazem das dificuldades e adversidades das suas atividades. Quando há corridas e taxas interpretadas como justas, atribuem à vontade de Deus, por exemplo. É comum e frequente, também, identificarem-se como "irmãos de profissão", em alusão a uma solidariedade horizontalizada semeIhante à religiosa, na qual "todos são iguais perante Deus". Esse é um fator que precisa ser aprofundando e compreendido por meio de pesquisas empíricas capazes de adentrarem em outros âmbitos da vida e de sociabilidade dos entregadores. Como hipótese correlata, explica-se a aversão a partidos políticos e a elementos culturalmente reconhecidos como de esquerda e de suas formas reconhecidas de mobilização e atividade política, como sindicatos. Portanto, faz-se necessário melhor compreender e relacionar o 
fenômeno do protestantismo no Brasil, suas práticas, valores e concepções de mundo e de trabalho. Como indicou Max Weber, a identidade de tipo profissional - Beruf, vocação, ou chamado de Deus para o trabalho - está afinada a um contexto religioso e cultural específico.

\section{Conclusões}

Os desafios introduzidos pelo modelo de negócio das plataformas digitais ultrapassam as fronteiras de uma única atividade, pois há um aspecto de heterogeneidade estrutural no modelo. Compreender seus impactos na configuração do trabalho dos entregadores pode nos fornecer indícios das tendências e linhas de força atuantes no capitalismo contemporâneo, ao mesmo tempo em que desvela a posição cada vez mais vulnerável do trabalho. As mobilizações e paralisações dos entregadores, mesmo com suas ambiguidades, evidenciam espaços de resistências emergentes. $\mathrm{Na}$ ausência de resistências e solidariedade, entra-se, na dicção de um dos entregadores, no "caminho para a morte". A vida digna e o trabalho justo são as principais motivações para a resistência e a solidariedade entre os entregadores.

A partir deste estudo, apontamos para a possibilidade de uma agenda de pesquisas, com investigações no sentido de apreender a emergência de formas de solidariedades difusas e complexas, que não simplesmente sobrescrevem as concepções de mobilização e de negociação alicerçadas na história trabalhista do século $\mathrm{XX}$, mas como também as articulam e as ressignificam frente às situações econômicas e sociais do nosso tempo.

Essas formações solidárias complexas manifestam a potência latente à abertura e à inclusão de multidões internamente diversificadas. O apoio da sociedade civil, consumidores, redes de juristas e acadêmicos denota a percepção de que a resistência às plataformas digitais não é horizonte apenas dos entregadores, mas condição para o convívio e bem comum de todos, sem o massacre. 


\section{Referências}

ABÍLIO, Ludmila Costhek et al. Condições de trabalho de entregadores via plataforma digital durante a Covid-19. Revista Jurídica Trabalho e Desenvolvimento Humano. Campinas, Edição especial - Dossiê Covid-19, p. 1-21, 2020. Disponível em: http://www. revistatdh.org/index.php/Revista-TDH/article/view/74/37. Acesso em: 31 jul. 2020.

ABILIO, Ludmila Costhek. Uberização: Do empreendedorismo para o autogerenciamento subordinado. Psicoperspectivas, Valparaíso, v. 18, n. 3, p. 41-51, nov. 2019.

ANTUNES, Ricardo. Trabalho intermitente e uberização do trabalho no limiar da Indústria 4.0. In: ANTUNES, Ricardo (coord.). Uberização, trabalho digital e Indústria 4.0. São Paulo: Boitempo, 2020. p. 11-22

ANTUNES, Ricardo. 0 privilégio da servidão: o novo proletariado de serviços na era digital. São Paulo: Boitempo, 2018.

AYTES, Ayhan. Return of the Crowds: Mechanical Turk and Neoliberal States of Exception. In: SCHOLZ, Trebor. Digital labor: the Internet as playground and factory. New York: Routledge, 2013. p. 100-125.

AZAIIS, Christian; DIEUAIDE, Patrick; KESSELMAN, Donna. Zone grise d'emploi, pouvoir de l'employeur et espace public: une illustration à partir du cas Uber. Relations industrielles, Québec, v. 72, n. 3, p. 433-456, 2017.

BOLDEN, Richard; MOSCAROLA, Jean. Bridging the QuantitativeQualitative Divide: The Lexical Approach to Textual Data Analysis. Social Science Computer Review, Londres, v. 14, n- 4, p. 450460, 2000.

BRASIL. STJ. Conflito de competência n 164.544/MG (2019/0079952-0). Ministro Relator Moura Ribeiro, Segunda Sessão, j. em 28 ago. 2019. 
CANTARELLA, Michelle; STROZZI,Chiara. Workers in the Crowd: The Labour Market Impact of the Online Platform Economy. IZA DP, Bonn-Alemanha, n. 12327, p. 1-44, 2019. ISNN: 2365-9793. Disponível em: http://ftp.iza.org/dp12327.pdf. Acesso em: 8 out. 2020.

CASTELLS, Manuel. The rise of the network society. Malden, MA: Blackwell, 1996.

DEGENNE, Alain; FORSE, Michel. Introducing social networks. London: Sage, 1999.

DEGRYSE, Christophe. Digitalisation of the economy and its impact on labour markets. Working Paper 2016.2. Brussels: European Trade Union Institute, 2016.

DEGRYSE, Christophe. Shaping the world of work in the digital economy. Foresight Brief. Brussels: European Trade Union Institute, 2017.

DUBET, François. Entretien avec François Dubet, Propos recueillis par Anne Dujin: "Imaginer de nouvelles solidarités". Esprit, Paris, v. 9, n. 9, p. 45-53, set. 2018.

DUBET, François. La préférence pour l'inégalité: comprendre la crise des solidarités. Paris: Republique des idees Seuil, 2014.

FREEMAN, Linton Clarke. A set of measures of centrality based on betweenness. Sociometry. Washington-DC, v. 40, p. 35-41, 1977.

FUCHTERMAN, Thomas M. J.; REINGOLD, Edward M. Graph Drawing by Force-directed Placement. Software-Practice and Experience. Melbourne, v. 21, n. 11, p. 1129-1164, 1991.

GONÇALVES, Carlos Manuel. Profissões e mercados: Notas e reflexão. Forum Sociológico, Lisboa, n. 15/16 (II Série), p. 1532, 2006. Disponível em: https://repositorio-aberto.up.pt/bitstream/10216/65771/2/carlosgoncalvesprofissoes000186626.pdf. Acesso em: 8 out. 2020. 
GONDIM, Sônia Maria Guedes. Grupos focais como técnica de investigação qualitativa: desafios metodológicos. Paidéia, Ribeirão Preto, v. 12, n. 24, p. 149-161, 2003.

HAMANN, Julian; SUCKERT, Lisa. Temporality in Discourse: Methodological Challenges and a Suggestion for a Quantified Qualitative Approach. Forum Qualitative Sozialforschung / Forum: Qualitative Social Research, Berlim, v. 19, n. 2, art. 2, 2018. Disponível em: http://dx.doi.org/10.17169/fqs-19.2.2954. Acesso em: 8 out. 2020.

HIGUCHI, Kenichi. KH Coder 3 Reference Manual. 2016. Disponível em: https://khcoder.net/en/manual_en_v3.pdf. Acesso em: 4 jun. 2020.

HIGUCHI, Kenichi. KH Coder. Versão 3.Beta.01b. 2020. Disponível em: https://github.com/ko-ichi-h/khcoder/releases/tag/3. Beta.01b. Acesso em: 4 jun. 2020.

HUWS, Ursula. Labor in the global digital economy: the cybertariat comes of age. Londres: Merlin, 2014.

LIMA, Jacob Carlos. Participação, empreendedorismo e autogestão: uma nova cultura do trabalho? Sociologias, Porto Alegre, a. 12, n. 25, set./dez, p. 158-198, 2010.

MACHADO, Sidnei. A greve dos entregadores e uma nova forma de organização na luta dos trabalhadores. Entrevista especial com Sidnei Machado. IHU On-line, 8 jul. 2020. Disponível em: http://www.ihu.unisinos.br/159-noticias/entrevistas/600717-a-greve-dos-entregadores-e-uma-nova-forma-de-organizacao-na-luta-dos-trabalhadores-entrevista-especial-com-sidnei-machado. Acesso em: 2 ago. 2020.

MACHADO, Sidnei. L'ubérisation du travail dans la jurisprudence brésilienne. Revue de droit comparé du travail et de la sécurité sociale, Bordeaux, v. 2, p. 76-81, 2019. 
MCAFEE, Andrew; BRYNJOLFSSON, Erik. Machine, platform, crowd: harnessing our digital future. New York: W.W. Norton \& Company, 2017.

LEHDOVIRTA, Vili. Algorithms that Divide and Unite:

Delocalisation, Identity and Collective Action in 'Microwork'. In: FLECKER, Jörg. (eds.) Space, Place and Global Digital Work. Dynamics of Virtual Work. Palgrave Macmillan: London, 2016. p. 53-80.

OIT. Las plataformas digitales y el futuro del trabajo: Cómo fomentar el trabajo decente en el mundo digital. Oficina Internacional del Trabajo. Genebra: OIT, 2019.

PARADEISE, Catherine. Les professions comme marchés du travail fermés. Sociologie et Société, Montréal, v. XX, p. 9-21, 1988.

PERKIN, Harold. The Rise of Professional Society: England Since 1880. London; New York: Routledge, 2002.

PFEFFER, Jürgen. Visualisierung Sozialer Netzwerke. In: STEGBAUER, Christian (ed.). Netzwerkanalyse und Netzwerktheorie. Wiesbaden: VS., 2008. p. 227-238.

SLEE, Tom. Uberização: a nova onda do trabalho precarizado. Trad. João Peres. São Paulo: Elefante, 2017.

SRNICEK, Nick. Platform capitalism. Cambridge, UK Malden, MA: Polity, 2017.

SUNDARARAJAN, Arun. The Sharing Economy. The End of Employment and the Rise of Crowd-Based Capitalism MIT Press, Cambridge, Massachusetts, 2016.

ZUBOFF, Shoshana. The age of surveillance capitalism: the fight for a human future at the new frontier of power. New York, NY: PublicAffairs, 2019. 